\title{
Imagining the Unimaginable: Communicating Extreme Volcanic Risk
}

\author{
Amy Donovan and Clive Oppenheimer
}

\begin{abstract}
This chapter considers the challenges surrounding the management of extreme volcanic risk. We examine eruption scenarios based on past episodes and assess the key issues that might arise should similar events occur in the future. The nature of such eruptions will entail transboundary and multi-scalar hazards. In a globalised world, the geopolitical and societal issues that are likely to emerge cannot all be predicted, and communication technologies themselves are likely to be affected. We explore two aspects: communication prior to the eruption, and communication during the eruption. To the best of our knowledge, all large eruptions are presaged by sensible phenomena but the enduring challenge for volcanic hazard assessment and risk management will remain the uncertainty surrounding evaluations of the likelihood, timing, nature and magnitude of potentially damaging activity. At present, too, communication of volcanic risk beyond the borders of the country where the volcano is located is generally patchy and unsystematic in most parts of the world (with the exception of the threat of ash clouds to aviation). In the preparatory phase, it is also critical to establish robust communication strategies that are resilient during an eruption. Such strategies would be essential for communicating the availability of supplies, the extent and nature of damage, and the ongoing status of the eruption.
\end{abstract}

A. Donovan $(\bowtie)$

Department of Geography, King's College London,

The Strand WC2R 2LS, UK

e-mail: amy.donovan@kcl.ac.uk

C. Oppenheimer

Department of Geography, University of Cambridge,

Downing Place, Cambridge CB2 3EN, UK

Advs in Volcanology (2018) 149-163

https://doi.org/10.1007/11157_2015_16

(C) The Author(s) 2016

Published Online: 26 March 2017 


\section{Introduction: Extreme Eruptions}

Large magnitude volcanic eruptions are rare events with typically long return-periods (less frequent than $\sim 1$ in 1000 years) at any single volcano (Oppenheimer and Donovan 2015). ${ }^{1}$ These range from large magnitude effusive basaltic lava eruptions to explosive super-eruptions. Basaltic lava eruptions, such as the 1783-4 Laki eruptions, are hazardous largely through their emissions of sulphur and halogens to the atmosphere, both locally and via long-range atmospheric transport. Such impacts include problems with air quality, disturbance of terrestrial and marine ecosystems, local contamination of water supplies (e.g. by fluorine leached from ash particles) and climate change. These eruptions may continue episodically for years. In contrast, large magnitude explosive eruptions usually last days or weeks, but can have more prolonged impacts. One estimate for an eruption with 100 times the sulphur yield of Pinatubo suggests that it would impact the climate strongly for approximately ten years (Timmreck et al. 2012). Such an event could have major impacts on food security, energy security and other critical networks.

The challenge of communicating these risks is multi-scalar and multi-dimensional: the potential impacts in the near-field to the far field are diverse, but are linked through the structures that manage them, such as local authorities and nation states. Such events and their impacts can transcend scale and are better defined by relationality: the relationships between groups of scientists with different responsibilities, political/policy groups, populations in different places, and a particular but as yet unidentified volcano. The volcano can be viewed as a geographical anchor in the physical landscape, to which different types of human network are connected. When we discuss communication of extreme volcanic risk, we are effectively examining the nature of the network connections and how they operate. Volcanic risk from large

\footnotetext{
${ }^{1}$ In this paper, we focus on the impact of large magnitude eruptions. However, we note that a smaller eruption at the wrong time and in the wrong place could produce an extreme event, and some of the implications discussed in this paper may be relevant to such a scenario.
}

eruptions is fundamentally a systemic risk of low probability but high impact. Communicating such risk requires a very broad approach: the events are potentially global, they would require management by institutions at multiple levels, and they would involve input from a very wide range of experts, stakeholders and citizens (Fig. 1).

Here, we concentrate on aspects of the problem in two different timeframes (pre-eruption and immediate) and two particular but overlapping communication types (those between scientists and policymakers, and between scientists and populations). Initially, we define two scenarios for a large magnitude eruption. We then focus on the nature of systemic risks, and explore generalities of the communication of global systemic risks, focussing on the pre-eruption timeframe (by which we mean the period prior to any detection of anomalous activity). We examine the immediate period, when signals are detected and then an eruption commences. We argue that these two timeframes are not entirely distinct: it is critical that relationships and knowledge exchange takes place pre-eruption in order that it underpins communication in an immediate setting. The subject of this paper is challenging because it deals with scenarios not experienced in recent history, and therefore the discussion is sometimes necessarily speculative. However, we have drawn on examples both from volcanic crises and from the wider risk literature.

\section{Volcanic Risk Scenarios}

In this section, we outline two particular extreme volcanic risks, and discuss the likely challenges presented by each. This provides the context for the subsequent discussion in the paper.

\subsection{Large Magnitude Basaltic Eruptions}

The 1783-4 Laki Fissure eruption has been extensively studied (e.g. Thordarson and Self 1993, 2003; Thordarson et al. 1996; Schmidt et al. 2011, 2012; Hartley et al. 2014). 
Fig. 1 Examples of the complex web of ideas, institutions, infrastructure and groups involved in the management of extreme volcanic risk

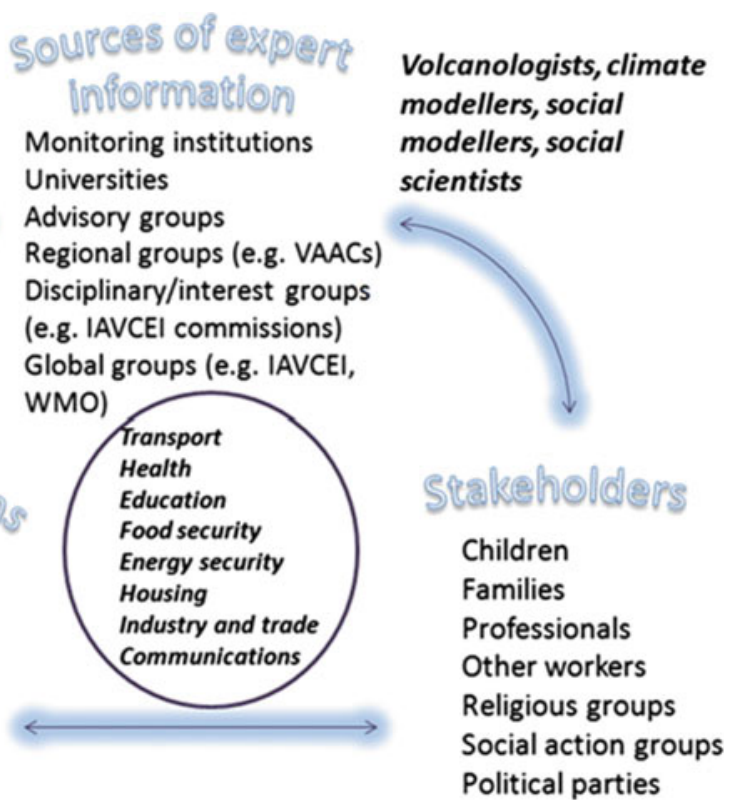

however, it is very challenging for volcanologists to forecast what is to the uncertainty in interpreting monitoring data from volcanoes, in general, is a theme that pervades the literature (e.g. Baxter et al. 2008; Marzocchi et al. 2012).

A large magnitude basaltic eruption could produce two primary hazards over large areasgas hazard and climate forcing. In the near-field, lava flows and tephra could be a problem. Gas hazard would affect the immediate area around the volcano, but its dispersion would be heavily dependent on the height of the plume and the meteorological conditions (e.g. Schmidt 2014). For example, $\mathrm{SO}_{2}$ from the Holuhraun eruption reached parts of Ireland and Norway (Schmidt et al. 2015; Gettelman et al. 2015). The extent of any climate forcing would be dependent on aerosol formation and transport, at least in the short term, and on the duration, seasonality and latitude of the eruption (e.g. Schmidt et al. 2012). In this scenario, then, the hazard would be spatially specific but long-range and variable. Forecasts of the hazard would be heavily dependent on meteorological data and models and source constraints-such as $\mathrm{SO}_{2}$ flux measurements and plume height distribution. Management of the hazard would defer to individual 
nation-states in the first instance, but in the event of more prolonged and regional scale climatic disturbance there would be a need for a collaborative response to manage any adverse impacts on food production and distribution. If the eruptions occur in a populated area and/or a small country, evacuations to other nations might be necessary. Air quality deterioration would affect healthcare provision, especially for those with existing respiratory illness. Air quality issues and airborne ash could also affect aviation at regional scale, and airspace closures would have to be managed reflexively during a long, fluctuating eruption.

\subsection{Large Magnitude Explosive Eruptions}

Large magnitude explosive eruptions (>M6, according to the scale of Mason et al. (2004)), and super-eruptions (M8) can result in regional to global scale effects on climate (depending on sulphur yield to the atmosphere, location and timing) and regional scale devastation. Climate impacts from a $100 \times$ Pinatubo $\mathrm{SO}_{2}$ release, for example, were modelled by Timmreck et al. (2012), and include decadal-scale global cooling of several degrees. This kind of scenario has major implications for food production globally. It would also affect trade, transportation and communication, particularly close to the source but with ripple-effects worldwide due to the nature of commercial aviation and global markets, and supply and distribution networks. Super-eruptions may even pose an existential risk (e.g. Rampino 2002). The complexities and diversity of the direct and indirect consequences of such large events make it very difficult to assess the risks in a meaningful way, and indeed it could be said that there have been no comprehensive efforts to assess the integrated impacts of a super-eruption on global society. Hereafter, we focus on an M8 scenario similar to that of the Youngest Toba Tuff (YTT) eruption, circa $74 \mathrm{ka}$ BP.
A large magnitude eruption would yield $>10 \mathrm{~km}^{3}$ of tephra in a matter of hours or days. In explosive eruptions of this size, substantial ash clouds are generated and associated plumes would circumnavigate the globe within a few weeks. Pyroclastic flows would likely extend tens of $\mathrm{km}$ from the volcano. The estimated minimum tephra mass for the YTT is $2 \times 10^{15} \mathrm{~kg}$ (Rose and Chesner 1990): an eruption of this magnitude could affect the continental scale with severe implications for farming and agriculture. A major uncertainty in such an eruption is the volatile budget. There has been considerable debate concerning the sulphur yield of the YTT eruption, for example (e.g. Rampino and Self 1992; Oppenheimer 2002; Williams 2012), and there is even less consensus on the halogen yields of such large eruptions. Cadoux et al. (2015) for example showed that halogen inputs from the large Minoan eruption of Santorini could have had significant impacts on atmospheric ozone. In any case, contamination of water supplies and ecosystems over large areas would likely lead to major food security problems. This could provoke or exacerbate epidemics and social unrest (Oppenheimer and Donovan 2015). While the prospect of such a global hazard can result in a return to environmental determinism (e.g. Rampino 2002), so widely condemned in the disasters literature (e.g. Raleigh et al. 2014), it nevertheless raises the question of global vulnerability and the complexity of networked societies and nations. While many studies have examined the impacts of past large magnitude eruptions (e.g. Oppenheimer 2011), there are no recent analogues to assess the impact of such an eruption on modern globalised society-particularly the impacts on technologies, including communication, transportation and power.

\subsection{Volcanic Risk Webs}

Approaches to volcanic eruption management have traditionally attempted to follow the so-called linear model, in which scientists 
produce evidence that they use for a risk assessment, which is then presented to policymakers who make decisions and then communicate those decisions to the public (e.g. Marzocchi et al. 2012). However, the empirical literature in volcanology and in other fields of environmental policy demonstrates that the linear model is flawed in practice because scientists and policymakers are part of the "public" and make social inferences throughout the process, as well as being affected by a range of political factors (e.g. Owens 2005; Owens et al. 2006; Jasanoff 1990, 2005; Donovan and Oppenheimer 2014). In essence, decision-making is networked and web-like, not linear, and communication and decision-making are not readily disentangled, since decisions will be interrogated by stakeholders. For example, during and after the 2010 eruption of Eyjafjallajökull in Iceland, the UK press attacked the Met Office's handling of the crisis (Harris 2015). Furthermore, large magnitude eruptions will not fit easily into human boundaries - national or institutional. Their management will depend not only on scientific monitoring and information, but also on the complicated networks of food production, security, transportation, electricity, political powers, water supply and communication, for exampleand on the connections and dependencies between these networks. Risks of large magnitude volcanic events are best conceptualised in the context of networks or webs of interactions between critical infrastructure, institutions, political powers and the Earth system itself.

In the event of a super-eruption, for example, the impacts on global aviation and even shipping would have major impacts on supply chains of both food and technology (see Fig. 2). This would be significantly compounded by poor harvests in regions affected by volcanically-forced climate change. Increased food prices can trigger or exacerbate civil unrest and public health problems, limiting economic growth (e.g. Benson and Clay 2004). Areas and nations less affected by transport restrictions or more self-sufficient in terms of food requirements would be able to adjust to some extent but a severe economic impact on key banks in, for example, East Asia, would cause liquidity crises in Europe and the United States.

As the eruption continues, or ash fallout across wide areas becomes re-suspended, much of the globe could have to manage repeated airspace closures and trade disruption. Climate impacts could be felt for years after the eruption (e.g. Timmreck et al. 2012), with poor harvests driving the global economy further into crisis and causing conflicts over resources (e.g. Godfray et al. 2010; see also Gassebner et al. 2010). Communication technologies could be badly affected as ashfall damages infrastructure including telecommunications masts, limiting the scope of cooperative risk management across and within national borders. In this scenario, we can only scope out the potential impacts, but several attempts have been made to rationalise such an extreme event (e.g. Denkenberger and Pearce 2014; Rees 2013). Modelling such events is highly complex, not least because it depends on numerous source factors which have large ranges (such as sulfur load, timing, location) as well as on the fragilities and vulnerabilities of the global food system, transport systems and governance systems. On top of this, uncertainty-both scientific and social-has to be taken into account to produce meaningful results. The problem is transdisciplinary because it requires action by experts (scientists, social scientists), governments and other stakeholders (Fig. 1). The uncertainty is therefore likely to be amplified because of the combination of monitoring methods, models and interpretation across different groups.

A further source of uncertainty is the transboundary nature of these large magnitude scenarios. Both of these scenarios pose challenges that transcend national boundaries, but will nevertheless be significantly affected by them, as nations differ in how they manage volcanic risk. At present, the management of volcanic risk is primarily the work and responsibility of individual nation states. Institutional frameworks vary considerably between nations (e.g. Donovan and Oppenheimer 2015a), and are not necessarily readily combined. Volcanoes are inevitably sited in particular places, and if other nations are affected by an eruption, they will be dependent at 


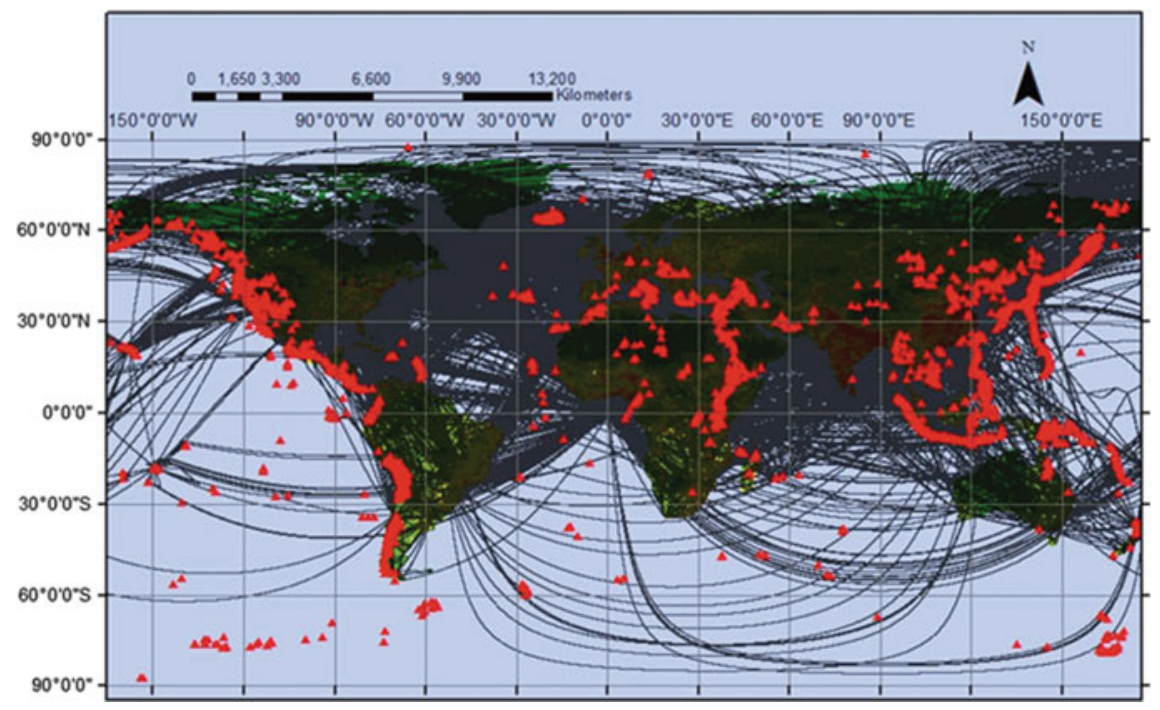

Fig. 2 Global flight routes (black lines). Also shown are volcanoes listed in the LaMEVE database (Crosweller et al. 2012) and population density (green to red)

least in part on the "host nation" for information. This has been demonstrated in recent eruptions in Iceland (Donovan and Oppenheimer 2012), and also in Ethiopia and Eritrea (where the lack of diplomatic relationships caused problems as well; Yirgu et al. 2014). Information about the eruption of Nabro volcano in Eritrea was primarily sourced from satellite data, demonstrating the importance and significance of recent developments in remote sensing of volcanoes (e.g. Biggs et al. 2014).

An additional challenge of transboundary events is the issue of consistency. Nations may vary in their responses to eruptions and in their willingness to issue evacuation orders. One country may evacuate its citizens from the immediate proximity of the volcano and another may not. In the event of threats to air quality from volcanic emissions, one country may provide free masks and another not. These factors are important because of the potential for the situation to be exacerbated by social unrest as citizens in one state feel less well provided-for than those in another. Hence, such an eruption could reverberate through global social networks, amplifying uncertainties and significantly affecting social stability. There are also spatial differences in vulnerability and exposure: societies will not be affected equally, and this could create significant challenges for security and for the allocation of resources. The Millennium Declaration, for example, states that "global challenges must be managed in a way that distributes the costs and burdens fairly in accordance with basic principles of equity and social justice" (UN General Assembly 2000, p. 1, paragraph 6). This effectively refers to "risk sharing": the principle that risk is reduced for those most affected if it is shared with those who are less affected. This would be challenging in the event of an M8 eruption in which there are global impacts, and requires careful planning at an international level prior to the event.

The probability of either of the scenarios in this paper being realised is very low, if it is based on frequency analysis of past events. Frequency-based probabilistic assessments are commonly used in volcanology as "base-rates" (e.g. Mader et al. 2006; Self 2006). However, as a volcanic crisis unfolds, additional information may become available - such as an increase in seismic activity for example. Many volcanologists would argue that this information suggests that there is an increased probability of an eruption-but a frequency-based analysis cannot incorporate this information as it generally 
requires higher levels of judgement, and belief-based probabilistic methods may be used (e.g. Bayesian methods, expert elicitation; Marzocchi et al. 2007; Aspinall et al. 2003; Newhall and Pallister 2014). The scenario then becomes a "single event" problem (Gigerenzer 1994). These two scenarios - the longer term risk from large magnitude eruptions and the immediate potential for such an eruption-represent our two timescales hereafter. Initially, we argue that the longer-term risk from these eruption scenarios requires engagement with policymakers at all levels to ensure that there is awareness of the risk-it has to be on the global agenda as a systemic risk. We then explore some of the implications of this for scientists. Finally we discuss the evolution of a scenario into a single event problem, and the ensuing challenges of communication.

\section{Systemic Volcanic Risk: Global Communication Structures and Decision-Making Systems}

Ultimately, the risks associated with these scenarios are systemic: they occur at the interface between the human and the physical, and require a holistic approach to risk management. According to Renn and Klinke (2004), "A holistic and systemic concept of risk must expand the scope of risk assessment beyond its two classic components: extent of damage and probability of occurrence." Haldane and May (2011) compare the complex systems of banking to the complexity of ecosystems, for example: there are multiple connections between actors and institutions that are dependent on one another and that transcend scale. Global systemic risk is a direct result of globalisation: it is a networked risk. While networks make risk more manageable in some ways by adding robustness, they can also increase fragility (Beale et al. 2011; Goldin and Vogel 2010), because a break in one part of the network affects the whole network.

The complexity of global networks sits uneasily with the existence of nation states (e.g. Sassen 2006): "bits of territory, authority and rights" are assembled on multiple scales that transcend the traditional "local to national to global" scalar distinctions. Sassen (2006) argues further that "new types of orderings" are emerging. The global community of volcanologists also exists in this precarious spot between national and global-volcano monitoring scientists work within the institutional structures of governments, yet also participate in a global scientific debate about methods, new interpretations and new data - all of which can feed into their work within a state. This can have the positive effect of adding robustness to risk management within a nation, but can also produce culture clashes between the scientific perception and the local response (e.g. Donovan et al. 2014a, b). Such culture clashes have materialised in connection with outputs from the Intergovernmental Panel on Climate Change (IPCC), for example (e.g. Hulme 2009, 2014), and also in debates in different countries about issues such as genetically-modified crops. The focus in discussions around the IPCC is not merely a result of the evidence and uncertainties, but also a matter of how evidence is presented (Hulme and Mahoney 2010).

Communication of extreme volcanic risk at a global scale is thus immensely complex. It is affected by geography - availability bias, for example, will make some people more readily able to conceive of volcanic impacts than others (Tversky and Kahneman 1974). There are cultural variations not only in the way that risk is perceived, but also in the way that it is managed (e.g. Dake 1992). In the case of extreme volcanic risk that affects multiple nations and cultures, effective communication would have to use a range of media, and would require the involvement of a wide range of actors and institutions with a consistent and culturally sensitive narrative.

\subsection{Managing Communication}

The volcanic ash advisory centres (VAACs) have some experience in communicating transboundary volcanic hazard from ash plumes. They 
require governments to monitor their volcanoes and provide information, usually via volcano observatories, when eruptions are imminent or ongoing. Models are run by the VAACs to assess the trajectory of ash clouds and information is provided for use by aviation authorities. It thus addresses a very specific problem with key actors who have some control over operations. However, the systematic allocation of areas of the globe to particular VAACs does ensure that responsibility is clear, and the information is available to those who need it in a straightforward way.

The requirement that there are global systems in place for managing global risks can, however, obfuscate the complexity of the problems at smaller scales. There is, for example, wide variation in the use of colour codes and alert levels between nations (and sometimes within them). This can depend on historical experience and on dominant types of volcanism, for example (e.g. Potter et al. 2014; Fearnley et al. 2012). The use of alert levels is also not very reliable at present (Winson et al. 2014). There are therefore some issues with any potential "global alert level system", and while there is a global aviation colour code system, it is hazard-specific to ash plumes that might affect aircraft.

The absence of any international mechanisms for volcanic risk assessment and communication is problematic for several reasons, not least because it means that any response will be reactive. Goldin and Vogel (2010) note that many of the "obvious" international decision-making institutions (such as the World Bank and United Nations) "are already overloaded": they have been stretched beyond their original remits by globalisation. Global governance itself is highly complex and driven by regulation, but it is also in its infancy, and is beset by issues such as the achievement of global democracy. There are also, importantly, much more pressing issues for global governance to deal with than the small possibility of a large magnitude eruption. Volcanologists are familiar with the difficulties of getting governments to act (e.g. Oppenheimer 2011): volcanoes are not that important. Hence there is no mechanism for international scientific advice in large magnitude events.

Recent work on volcano early warning systems (e.g. Fearnley et al. 2012; Potter et al. 2014; Winson et al. 2014) has demonstrated some of the challenges of applying such systems in practice. Similarly, work on scientific advisory mechanisms has also demonstrated their social complexity (Donovan and Oppenheimer 2015b; see also for example Hulme 2014 on the IPCC). Nevertheless there is a strong argument that mechanisms for providing global warnings about volcanic activity are needed. It is worth noting that the Sendai Framework for Disaster Risk Reduction 2015-2030 called for a greater role for science (including social, economic, engineering, physical and medical sciences) in disaster risk reduction, and this presents an opportunity for the development of international advisory systems that fully integrate expertise from all of these fields, learning from the experiences of similar bodies such as the IPCC.

Rare events require three things from scientific advisors: imagination, flexibility and rapid response. Even where governments have no interest in preparing, scientists can be ready to offer advice: after all, governments will want it quickly when the need arises! In spite of this, there is a need for at least a mechanism for scientific advice during large magnitude eruptions. The model of the Volcanic Disasters Assistance Program is useful here-it gives precedence to local scientists whilst also providing resources (Pallister 2015). A further consideration, however, is the integration of social sciences throughout the processes of risk assessment and communication. Risk communication in an extreme event would require several characteristics: consistency, transparency and reflexivity. Consistency does not mean that the communication should always say the same thing about the risk; it rather means that messages should be internally consistent and clear about what is and is not known. It can be damaging when one group claims to have better information than another. This is therefore aided by transparency about the information itself and how it is being used, as well as about uncertainty. Reflexivity 
refers to the subjectivity of those doing the communicating, and how they manage it (Donovan et al. 2014b; see also Alvesson and Sköldberg 2009; Gibbons et al. 1994, for general discussions of reflexivity). This requires a level of personal integrity and self-awareness. It becomes threatened if the communicator has too much emotional investment in the information, for example.

\subsection{The Nature of Communication}

The systemic nature of these risks requires a long-term scientific and social scientific engagement with decision makers in international, regional, national and local institutions (see Fig. 1). Work in risk communication has demonstrated unequivocally that communication links that are established prior to a crisis are critical in facilitating communication during a crisis (e.g. Donovan and Oppenheimer 2012; Marzocchi et al. 2012; Barclay et al. 2008; Bird et al. 2008; Haynes et al. 2008). One key recommendation is therefore that experts ensure that they are in communication with civil protection organisations even when volcanic activity is low. Such contact does not have to be continuous, but it should be relatively regular (for example, a meeting every six months - though this is likely to vary between institutions and circumstances). Meetings might include simulated drills, discussions of earthquake activity and monitoring data over the last few months, updates on response plans and discussion of new results.

Risk communication has different requirements depending on whether one considers high-frequency low impact events or low-frequency high impact events, especially at the extreme event end of the scale. This requires judgement: one of the problems with extreme events that have low probabilities but high impacts is that they can capture scientists' and journalists' imaginations. As Pidgeon and Fischoff (2011) point out, listening is also a form of communication, and so is silence. Govern- ments have struggled to identify the "right" time to tell populations about extreme risks, and survey respondents generally want to be told but recognise that the issue is ambiguous (e.g. Eiser et al. 2014; Donovan et al. 2014a, b). In general, low probability risks are communicated if the probability increases. Setting a threshold for this can, however, be challenging because of the fear of "false alarms". Volcanologists have struggled with this balance in the past, and this has fed into studies to find appropriate statistical approaches (e.g. Woo 2008; Aspinall et al. 2003). Successful management depends on the communication not only of risk but of uncertainty. In the presence of high uncertainty, there is no such thing as a false alarm (e.g. Hincks et al. 2014, showed that the evacuations on Guadeloupe in 1976 were justified even though there was no eruption, because there was very high uncertainty). However, high uncertainty regarding a low probability but high impact risk is challenging, and is also a situation in which the precautionary principle can produce paralysis rather than rational decisions (e.g. Sunstein 2005), not least because of the high economic cost of always erring on the side of precaution. With regard to extreme volcanic risk pre-crisis, communication with the public has to be carefully considered and framed. It also has to be transparent: the results of the L'Aquila trial demonstrate the importance of clear and open communication, for example. After the 2009 earthquake, inhabitants felt that they had been misled because they had been explicitly reassured (Alexander 2014), rather than told that the risk was low but not zero.

Framing is a critical aspect of risk communication (e.g. Barclay et al. 2008). A frame is a social construct that allows the interpretation of complex information. Frames can be negotiated through dialogue between all the participants in a conversation to ensure that they are appropriate and effective. It is important not only to state scientific knowledge and uncertainty, but also to engage with the audience. Scientists' perceptions of the audience are also likely to affect their communication (Donovan et al. 2014a) and must 
be handled carefully. This is a subjective process, but can be rationalised through collaboration and discussion between physical scientists, social scientists, policymakers and the public.

\section{Single Event Communication}

Once volcanic activity is detected and expert opinion is that the eruption may be very large, the volcanic risk web has to be "activated". Figure 3 is a map of the world showing the location of tweets with the hashtag \#Holuhraun from 29 August to 2 September 2014 (there was a small eruption on 29 August, and then the fissure re-opened from 31 August 2014 to 27 February 2015). It demonstrates the velocity with which information about volcanic eruptions travels the web. Secrecy about a potential large eruption would be very difficult to maintain for any length of time. Ultimately, the communication of such risk would be the responsibility of governments, but it would be strongly dependent upon relationships between scientists, social scientists and governments - and the trust that is placed in them by industry, NGOs and other stakeholders, including the public.

In Donovan et al. (2012), we introduced a modified framework for the management of risk in volcanic crises, based on the Science Studies literature (Wynne 1992; Stirling 2007). A simplified version of this is shown in Fig. 4, demonstrating the transdisciplinary nature of the problem: the types of question that are generated from such a systemic risk are multi-dimensional. There are risks, uncertainties, ambiguities and ignorance that affect multiple connected groups and entities.

The management of such a situation would quickly escalate beyond nations, and require coordination (e.g. by UN institutions). It would require coherence and clarity about the potential impacts of the eruption, and about its management by different groups in the risk web (e.g. distinguishing the responsibilities of government from those of individuals). In this respect, the communication of risk moves far beyond volcanologists - but also requires that volcanologists retain their integrity as sources of expert information. In the next subsection, therefore, we discuss some of the broad issues that affect

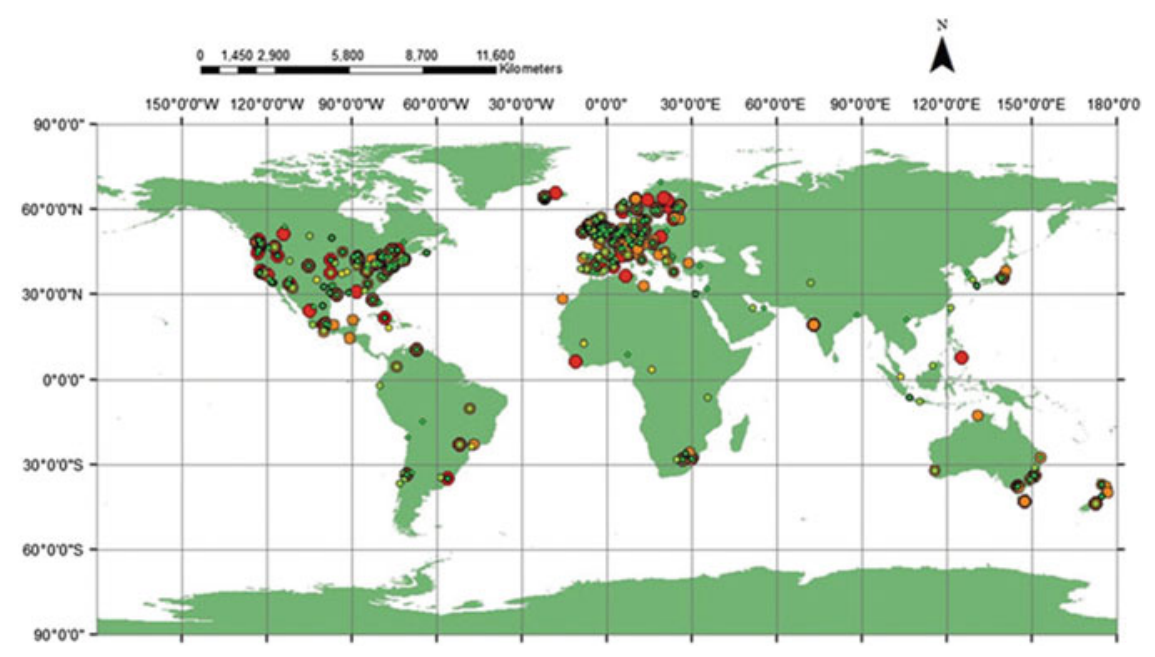

Fig. 3 Tweet map, showing tweets with the hashtag \#Holuhraun between 29 August and 2nd September. Colours and size represent the day: red 29 August, orange 30 August, yellow 31st August, light green 1 Sept, dark green 2 Sept. Note that only tweets from users who disclose their geolocation can be mapped; this amounts to $\sim 2500$ tweets, of a total of $\sim 5600$ 


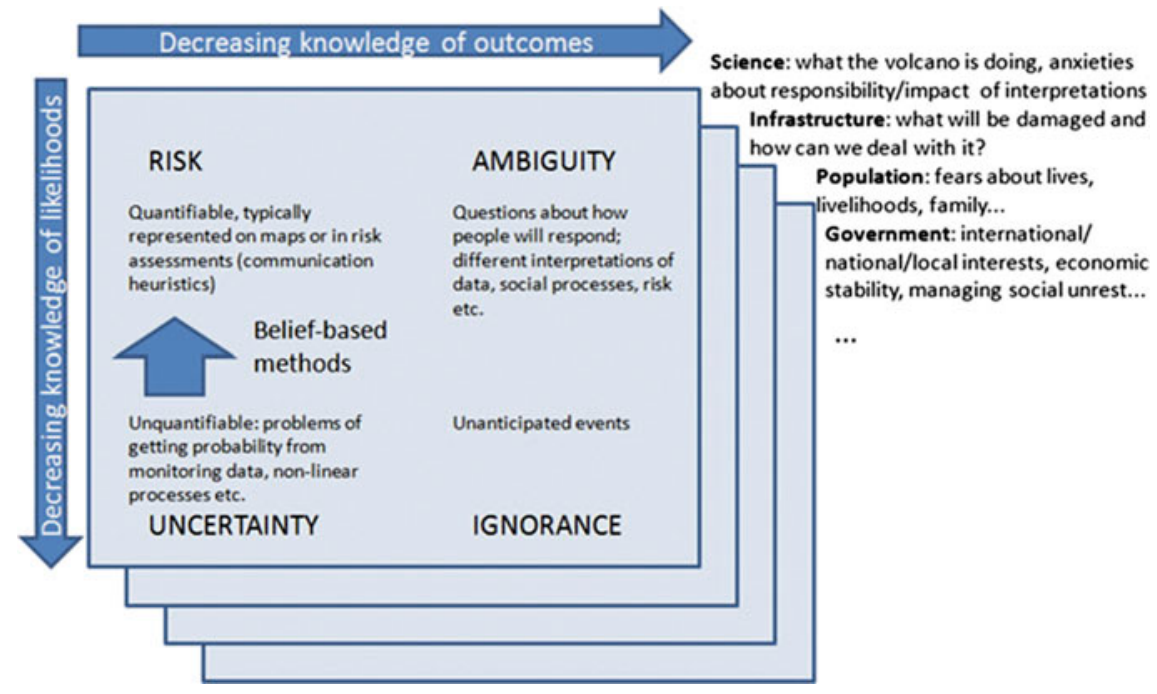

Fig. 4 Different aspects of uncertainty around volcanoes, modified from Stirling (2007), Wynne (1992) and Donovan et al. (2012). Each category represents a different aspect of uncertainty that will be represented in each part

volcanologists involved in expert advice. This affects both long-term and single event communication: we suggest that the communication of extreme volcanic risk, though conceptually broken into these two aspects, actually depends on their integration. The management of an extreme volcanic event is likely to be dependent upon communication networks that are instituted prior to the detection of activity.

\subsection{Professionalising Volcanology}

Some of the issues that have been raised in this chapter speak directly to IAVCEI's Crisis Protocols (Newhall et al. 1999). Recent events, such as the trial of six seismologists in L'Aquila, Italy (e.g. Marzocchi 2012; Alexander 2014) have led to renewed calls for protocols and guidance for volcanologists who are involved in policy advice (e.g. Aspinall 2011). Volcanology in certain circumstances comes to resemble a formal profession (such as medicine or law; Baxter et al. 2008). In light of social media developments as well as an increasingly litigious world, the importance of individual responsibility cannot be of a network, including scientific institutions, infrastructure (transport, energy, agriculture etc), government institutions and different social groups

ignored in the context of global risk. Figure 3, for example, shows that the interest in the Holuhraun eruption was global and not scaled. In Iceland, researchers were asked not to tweet photos of themselves that were inconsistent with doing scientific work: the government was under pressure to allow tourists into the restricted area, which was a flood plain that would be affected rapidly in the event of subglacial eruption. The additional requirement to monitor social media sites may be an important consideration for future planning by volcano monitoring institutions. The interest and availability of information about volcanic activity-without any quality controls - is therefore challenging to manage. Communication technologies such as Twitter and Facebook are double-edged: they can both complicate and aid disaster management. Furthermore, they may require additional resources from responsible institutions in the event of a crisis. Where there is potential for a large magnitude eruption-for example, an unrest episode at a known supervolcano - it is likely that media attention would be significant and that volcanologists around the world might be asked to comment on a volcano about which they know 
relatively little. The likely involvement of the global volcanology community in a large magnitude event necessitate a brief consideration of these issues here.

The implications of this for researchers are, ultimately, value-driven: they require reflexive management of subjective tendencies to want to be involved in every volcanic crisis, and careful consideration of comments on social media, following professional guidelines (e.g. from IAVCEI). Awareness that there may be a political context that individuals at a distance cannot see is also important. However, there are also implications for volcano monitoring institutions, particularly concerning the need to monitor social media but also its potential. Bird et al. (2008) demonstrated that the level of information provided by the Icelandic Meteorological Office on its website was appreciated by the public. Donovan and Oppenheimer (2012) found that scientists interviewed in Iceland felt that the availability of data had led to the public becoming, over time, able to use that information effectively. There are considerable advantages to a long-term dialogue with the public that familiarises people with the kinds of information available in a crisis - though there may be disadvantages and understandable insecurities in making data too readily available, not least the potential for misinterpretation (Donovan and Oppenheimer 2015a, b). Again, this issue is magnified in the case of supervolcanoes, as data indicating an increase in activity might cause widespread concern.

A further uncertainty in the present caselarge magnitude eruptions - is that the source volcano may not have received much attention, compared with frequently active systems such as Etna. There may well be a trade-off between the involvement of scientists who have experience in policy advice but no local knowledge, and the involvement of, for example, a single local scientist who happened to do their PhD studies on that volcano, but is considerably more familiar with petrological methods than with providing hazard advice. Again, reflexivity is an approach that may aid in this situation.
Comparisons have been made in the past between volcanology and medicine (e.g. Baxter et al. 2008), and the introduction of "evidence-based volcanology" (Aspinall et al. 2003) builds on ideas from the medical literature. One difference is that volcanologists do not take the Hippocratic Oath and are not trained to deal with people or indeed to refer patients to colleagues whose specialties might be more appropriate. The culture of academia in particular is not always conducive to effective delegation or humility, and academics are not trained for the high pressure of responsibility for matters of life and death. The detection of signals that suggest a potentially large magnitude eruption at a previously unstudied volcano would have major impacts on the expectations that the public have of volcanologists, and on the pressure and responsibility faced by experts. Academic training, at present, rarely includes mandatory training in science communication for policy, or indeed in statistics for risk assessment-but volcanology is slowly turning into a profession, and this requires some adjustments in pedagogy.

\section{Conclusions}

This chapter has addressed some of the issues around the communication of extreme volcanic risk. We have demonstrated that such a risk is fundamentally systemic, not local, and it transcends scale. It is a networked risk that can be visualised as a web of connections between governments, institutions, infrastructures, industry, experts and populations, and "grounded" geographically through an as-yet-unspecified volcano. Such an event would reverberate through the risk web, and requires transdisciplinary collaboration. It is therefore important that communication pathways are established prior to any eruption. Communication about extreme volcanic risk prior to the detection of any activity will dictate the nature of communication when activity is detected. It should be characterised by four ideas: 
- Appropriate framing: this requires careful consideration of the social context of the scientific information and also the potential impacts that it might have on the population.

- Intersubjective validation: this represents the importance of some level of scientific consensus - peer review-so that messages are clear.

- Dialogue and listening: communication is a two-way process, and this means that concerns from policymakers and populations have to be taken seriously and addressed

- Reflexive adaptation: in a rapidly developing situation, it is important that individual fears, assumptions and anxieties are acknowledged and addressed within the communication process.

These concepts are suggested as a means of structuring discussions between social and physical scientists, policymakers, officials and populations: they require transdisciplinary discussions. In the event of an imminent large-magnitude eruption, there will not be time to build relationships from scratch, nor to debate the appropriate role of different stakeholders and experts. Experts and civil institutions have to work together both to establish relationships and to assess existing communication technologies for their resilience to large magnitude hazards. However, much of this is required at a political level. The management of the high uncertainty in volcanic crises, the communication challenges and the need for engagement over the long term suggest that volcanology is becoming a profession in which agreed standards for practice are required.

Open Access This chapter is distributed under the terms of the Creative Commons Attribution-NonCommercial 4.0 License (http://creativecommons.org/licenses/by-nc/4. $0 /$ ), which permits any noncommercial use, duplication, adaptation, distribution, and reproduction in any medium or format, as long as you give appropriate credit to the original author(s) and the source, a link is provided to the Creative Commons license, and any changes made are indicated. The images or other third party material in this chapter are included in the work's Creative Commons license, unless indicated otherwise in the credit line; if such material is not included in the work's Creative
Commons license and the respective action is not permitted by statutory regulation, users will need to obtain permission from the license holder to duplicate, adapt, or reproduce the material.

\section{References}

Alvesson M, Sköldberg K (2009) Reflexive methodology: New vistas for qualitative research. Sage, Beverly Hills

Alexander DE (2014) Communicating earthquake risk to the public: the trial of the "L'Aquila Seven". Nat Hazards 72(2):1159-1173

Aspinall WP, Woo G, Voight B, Baxter PJ (2003) Evidence-based volcanology: application to eruption crises. J Volcanol Geoth Res 128(1):273-285

Aspinall W (2011) Check your legal position before advising others. Nature 477:251

Barclay J, Haynes K, Mitchell T, Solana C, Teeuw R, Darnell A, Kelman I et al (2008) Framing volcanic risk communication within disaster risk reduction: finding ways for the social and physical sciences to work together. Geol Soc Lond Spec Pub 305(1):163177

Baxter PJ, Aspinall WP, Neri A, Zuccaro G, Spence RJS, Cioni R, Woo G (2008) Emergency planning and mitigation at Vesuvius: a new evidence-based approach. J Volcanol Geoth Res 178(3):454-473

Beale N, Rand DG, Battey H, Croxson K, May RM, Nowak MA (2011) Individual versus systemic risk and the Regulator's Dilemma. Proc Natl Acad Sci 108 (31):12647-12652

Benson C, Clay EJ (2004) Understanding the economic and financial impacts of natural disasters. World Bank Publications

Biggs J, Ebmeier SK, Aspinall WP, Lu Z, Pritchard ME, Sparks RSJ, Mather TA (2014) Global link between deformation and volcanic eruption quantified by satellite imagery. Nat Commun 5

Bird D, Roberts MJ, Dominey-Howes D (2008) Usage of an early warning and information system web-site for real-time seismicity in Iceland. Nat Hazards 47(1):7594

Cadoux A, Scaillet B, Bekki S, Oppenheimer C, Druitt TH (2015) Stratospheric Ozone destruction by the Bronze-Age Minoan eruption (Santorini Volcano, Greece). Scientific reports, 5

Crosweller HS, Arora B, Brown SK, Cottrell E, Deligne NI, Guerrero NO, Venzke E et al (2012) Global database on large magnitude explosive volcanic eruptions (LaMEVE). J Appl Volcanol 1(1):113

Dake K (1992) Myths of nature: culture and the social construction of risk. J Soc Issues 48(4):21-37

Denkenberger D, Pearce JM (2014) Feeding everyone no matter what: managing food security after global catastrophe. Academic Press, London 
Donovan A, Oppenheimer C (2015a) At the mercy of the mountain? Field stations and the culture of volcanology. Environ Plan A Abstr 47(1):156-171

Donovan AR, Oppenheimer C (2015b) Modelling risk and risking models: The diffusive boundary between science and policy in volcanic risk management. Geoforum 58:153-165

Donovan A, Oppenheimer C (2012) Governing the lithosphere: insights from Eyjafjallajökull concerning the role of scientists in supporting decision-making on active volcanoes. J Geophys Res Solid Earth (19782012):117(B3)

Donovan A, Oppenheimer C (2014) Extreme volcanism: disaster risks and societal implications. Extreme Nat Hazards, Disaster Risks Soc Implic 1:29

Donovan A, Oppenheimer C, Bravo M (2012) Science at the policy interface: volcano-monitoring technologies and volcanic hazard management. Bull Volcanol 74 (5):1005-1022

Donovan A, Eiser JR, Sparks RSJ (2014a) Scientists' views about lay perceptions of volcanic hazard and risk. J Appl Volcanol 3(1):1-14

Donovan A, Oppenheimer C, Bravo M (2014b) Reflexive volcanology: 15 years of communicating risk and uncertainty in scientific advice on Montserrat. Geol Soc Lond Mem 39(1):457-470

Eiser JR, Donovan A, Sparks RSJ (2014) Risk perceptions and trust following the 2010 and 2011 Icelandic Volcanic Ash Crises. Risk Anal

Fearnley CJ, McGuire WJ, Davies G, Twigg J (2012) Standardisation of the USGS volcano alert level system (VALS): analysis and ramifications. Bull Volcanol 74(9):2023-2036

Gassebner M, Keck A, Teh R (2010) Shaken, not stirred: the impact of disasters on international trade. Rev Int Econ 18(2):351-368

Gettelman A, Schmidt A, Kristjánsson JE (2015) Icelandic volcanic emissions and climate. Nat Geosci

Gibbons M, Limoges C, Nowotny H, Schwartzman S, Scott P, Trow M (1994) The new production of knowledge: the dynamics of science and research in contemporary societies. Sage, Beverly Hills

Gigerenzer G (1994) Why the distinction between single-event probabilities and frequencies is important for psychology (and vice versa). In: Wright $G$, Ayton P (eds) Subjective probability. John Wiley, New York, pp 129-161

Godfray HCJ, Beddington JR, Crute IR, Haddad L, LawrenceD Muir JF, Toulmin C (2010) Food security: the challenge of feeding 9 billion people. Science 327 (5967):812-818

Goldin I, Vogel T (2010) Global governance and systemic risk in the 21st century: lessons from the financial crisis. Global Policy 1(1):4-15

Haldane AG, May RM (2011) Systemic risk in banking ecosystems. Nature 469(7330):351-355

Harris A (2015) Forecast communication through the media Part 1: Framing the forecaster. Bull Volcanol $77: 29$
Hartley ME, Maclennan J, Edmonds M, Thordarson T (2014) Reconstructing the deep CO 2 degassing behaviour of large basaltic fissure eruptions. Earth and Planetary Science Letters 393:120-131

Haynes K, Barclay J, Pidgeon N (2008) The issue of trust and its influence on risk communication during a volcanic crisis. Bull Volcanol 70(5):605-621

Hincks TK, Komorowski JC, Sparks SR, Aspinall WP (2014) Retrospective analysis of uncertain eruption precursors at La Soufrière volcano, Guadeloupe, 197577: volcanic hazard assessment using a Bayesian Belief Network approach. J Appl Volcanol 3(1):1-26

Hulme M (2009) Why we disagree about climate change: understanding controversy, inaction and opportunity. Cambridge University Press, Cambridge

Hulme M (2014) Behind the curve: science and the politics of global warming. Clim Change 126(34):273-278

Hulme M, Mahoney M (2010) Climate change: what do we know about the IPCC? Progress Phys Geogr

Jasanoff S (1990) The fifth branch: science advisers as policymakers. Harvard University Press, Harvard

Jasanoff S (2005) Designs on nature: science and democracy in Europe and the United States. Princeton University Press, Princeton

Mader HM, Coles SG, Connor CB, Connor LJ (ed) (2006) Statistics in volcanology. Geol Soc Lond

Marzocchi W (2012) Putting science on trial. Physics World

Marzocchi W, Newhall C, Woo G (2012) The scientific management of volcanic crises. J Volcanol Geoth Res 247:181-189

Marzocchi W, Sandri L, Selva J (2007) BET_EF: a probabilistic tool for long-and short-term eruption forecasting. Bull Volcanol 70(5):623-632

Mason BG, Pyle DM, Oppenheimer C (2004) The size and frequency of the largest explosive eruptions on Earth. Bull Volcanol 66(8):735-748

Newhall CG, Pallister JS (2014) Using multiple data sets to populate probabilistic volcanic event trees. Volc Hazards Risks Disasters 203

Newhall C, (IAVCEI Subcommittee on Crisis Protocols) et al (1999) Professional conduct of scientists during volcanic crises. Bull Volc 60(5):323-334

Oppenheimer C, Donovan AR (2015) On the nature and consequences of super-eruptions. In: Schmidt A et al (eds) Volcanism and global environmental change. Cambridge University Press, Cambridge

Oppenheimer C (2002) Limited global change due to the largest known quaternary eruption, Toba $\approx 74 \mathrm{kyr} \mathrm{BP}$ ? Quatern Sci Rev 21(14):1593-1609

Oppenheimer C (2011) Eruptions that shook the world. Cambridge University Press, Cambridge

Owens S (2005) Making a difference? Some perspectives on environmental research and policy. Trans Inst $\mathrm{Br}$ Geogr 30(3):287-292

Owens S, Petts J, Bulkeley H (2006) Boundary work: knowledge, policy, and the urban environment. Environ Plan C 24(5):633 
Pallister J (2015) Volcano disaster assistance program: preventing volcanic crises from becoming disasters and advancing science diplomacy. Global Volc Hazards Risk 379

Pidgeon N, Fischhoff B (2011) The role of social and decision sciences in communicating uncertain climate risks. Nat Clim Change 1(1):35-41

Potter SH, Jolly GE, Neall VE, Johnston DM, Scott BJ (2014) Communicating the status of volcanic activity: revising New Zealand's volcanic alert level system. J Appl Volcanol 3(1):1-16

Raleigh C, Linke A, O’Loughlin J (2014) Extreme temperatures and violence. Nat Clim Change 4 (2):76-77

Rampino MR (2002) Super-eruptions as a threat to civilizations on earth-like planets. Icarus 156:562-569

Rampino MR, Self S (1992) Volcanic winter and accelerated glaciation following the Toba super-eruption. Nature 359(6390):50-52

Rees M (2013) Denial of catastrophic risks. Science 339 (6124):1123

Renn O, Klinke A (2004) Systemic risks: a new challenge for risk management. EMBO Rep 5(S1):S41-S46

Rose WI, Chesner CA (1990) Worldwide dispersal of ash and gases from earth's largest known eruption: Toba, Sumatra, 75 ka. Palaeogeogr Palaeoclimatol Palaeoecol 89(3):269-275

Sassen S (2006) Territory, authority, rights: from medieval to global assemblages, vol 7. Princeton University Press, Princeton

Schmidt A, Leadbetter S, Theys N, Carboni E, Witham CS, Stevenson JA, Shepherd J et al (2015) Satellite detection, long-range transport and air quality impacts of volcanic sulfur dioxide from the 2014-15 flood lava eruption at Bárðarbunga (Iceland). J Geophys Res Atmos

Schmidt A, Thordarson T, Oman LD, Robock A, Self S (2012) Climatic impact of the long-lasting 1783 Laki eruption: inapplicability of mass-independent sulfur isotopic composition measurements. J Geophys Res Atmos (1984-2012):117(D23)

Schmidt A, Ostro B, Carslaw KS, Wilson M, Thordarson T, Mann GW, Simmons AJ (2011) Excess mortality in Europe following a future Laki-style Icelandic eruption. Proc Natl Acad Sci 108 (38):15710-15715

Schmidt A (2014) Volcanic gas and aerosol hazards from a future Laki-type eruption in Iceland. Volc Hazards Risks Disasters 377

Self S (2006) The effects and consequences of very large explosive volcanic eruptions. Philos Trans R Soc A: Math Phys Eng Sci 364(1845):2073-2097
Sigmundsson F, Hooper A, Hreinsdóttir S, Vogfjörd KS, Ófeigsson BG, Heimisson ER, Eibl EP et al (2014) Segmented lateral dyke growth in a rifting event at Bar [eth] arbunga volcanic system, Iceland. Nature

Stirling A (2007) Risk, precaution and science: towards a more constructive policy debate. EMBO Rep 8 (4):309-315

Sunstein CR (2005) Laws of fear: beyond the precautionary principle (vol 6). Cambridge University Press, Cambridge

Thordarson T, Self S (1993) The Laki (Skaftár Fires) and Grímsvötn eruptions in 1783-1785. Bull Volcanol 55 (4):233-263

Thordarson T, Self S (2003) Atmospheric and environmental effects of the 1783-1784 Laki eruption: a review and reassessment. J Geophys Res: Atmos (1984-2012):108(D1), AAC-7

Thordarson T, Self S, Oskarsson N, Hulsebosch T (1996) Sulfur, chlorine, and fluorine degassing and atmospheric loading by the 1783-1784 AD Laki (Skaftár Fires) eruption in Iceland. Bull Volcanol 58(2-3):205225

Timmreck C, Graf HF, Zanchettin D, Hagemann S, Kleinen T, Krüger K (2012) Climate response to the Toba super-eruption: regional changes. Quatern Int 258:30-44

Tversky A, Kahneman D (1974) Judgment under uncertainty: heuristics and biases. Science 185(4157):11241131

UN General Assembly (2000) United Nations Millennium Declaration. Resolution A/55/L.2

Williams M (2012) Did the 73 ka Toba super-eruption have an enduring effect? Insights from genetics, prehistoric archaeology, pollen analysis, stable isotope geochemistry, geomorphology, ice cores, and climate models. Quatern Int 269:87-93

Winson AE, Costa F, Newhall CG, Woo G (2014) An analysis of the issuance of volcanic alert levels during volcanic crises. J Appl Volcanol 3(1):1-12

Woo G (2008) Probabilistic criteria for volcano evacuation decisions. Nat Hazards 45(1):87-97

Wynne B (1992) Uncertainty and environmental learning: reconceiving science and policy in the preventive paradigm. Glob Environ Change 2(2):111-127

Yirgu G, Ferguson DJ, Barnie TD, Oppenheimer C (2014) Recent volcanic eruptions in the Afar rift, northeastern Africa, and implications for volcanic risk management in the region. Extreme Nat Hazards Disaster Risks Soc Implic 1:200 